\title{
Damage Analysis of Moldboard Plow
}

\author{
Diah Kusuma Pratiwi ${ }^{1}$, Hendri Chandra ${ }^{1,{ }^{*}}$, , Nurhabibah Paramitha Eka Utami $^{1}$, Okta \\ Irawan $^{1}$, and Arman Natal Purba ${ }^{1}$ \\ ${ }^{1}$ Department of Mechanical Engineering, Universitas Sriwijaya, 30662, Indralaya, South Sumatera, \\ Indonesia
}

\begin{abstract}
Moldboard plow is a tool used to cultivate the agricultural land. The material of the moldboard is a double layer where the outer layer is high carbon steel and the inside is a low carbon steel. The findings on the side edge of the moldboard plow are often damaged due to bent deformation and then broken. The study was conducted to determine the cause of the damage through simulation and testing laboratory. The simulation results show that the moldboard is overloaded by its material capability. This is shown also from the results of testing the chemical composition that this material is a low-alloy steel single layer without surface hardening. Hardness tests conducted using Rockwell $\mathrm{C}$ show that this steel has a tensile strength of only about $400 \mathrm{MPa}$. This is reinforced by the results of microstructural observations showing that more than $99 \%$ of the phases are ferrite.
\end{abstract}

\section{Introduction}

Indonesia is an agrarian country where many people live from agricultural cultivation. This farming process involves the process of planting seedlings, preserving by giving fertilizer and providing protection from crop diseases and weeds, until then harvested. Physical and mechanical soil processing before being ready for planting is called tillage. Tillage consists of primary and secondary processes. Primary land preparation operations are the primary initial operations of the land; it is usually designed to reduce soil strength, cover up the remaining plant material and rearrange aggregates. Secondary land preparation operations are intended to create better soil conditions after primary tillage.

Primary land preparation operations use tools to plow the land. For thousands of years B.C people have used a kind of plow. This type of plow is changing from year to year with the development of ideas from plow farmers to improve existing plows. In 1721, the Nolfork peasants began to use a curved wheel-shaped iron rod. Later in 1760 Suffolk farmers used a curved moldboard spade. Late in the eighteenth-century farmers in Britain changed from wooden plows to iron plows [1].

The bottom of the moldboard plow is a land-processing tool where the first one is defined as individual work-ground elements. Finally, the tillage work, consisting of a single tool or a group of tools' together with the corresponding frame, wheels etc. The bottom plow is the most important part of the plow [2] 
Currently, multiple moldboard plows are used as shown in Figure 1 (a) and (b) show the bottom of the moldboard plow. The edge of the moldboard is the most easily cracked, broken, or deformed plastic part.

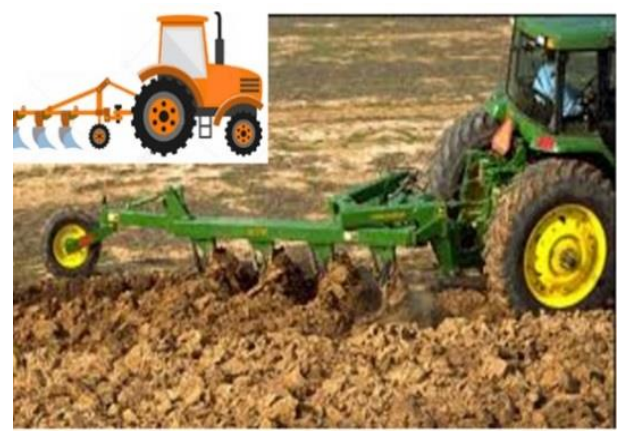

Fig. 1. Multiple moldboard plow

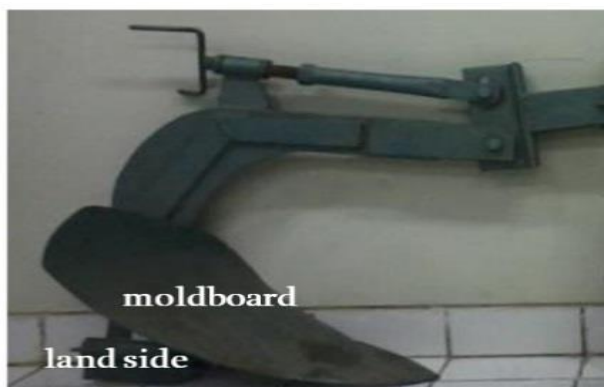

Fig. 2. The bottom of moldboard plow

The purpose of this paper is to learn about the damage to the plow board. Modes of this type of damage often occur in pirated. This case caused the operation of primary land preparation to be disturbed. This research was conducted to understand the causes of damage using simulation methods of stress analysis and laboratory testing to determine the chemical composition, hardness, and micro moldboard material. It is expected that the results of this study will help farmers in overcoming the damage that often occurs in the plow.

\section{Materials and Methods}

\subsection{Chemical Composition}

Moldboard usually is made of two layers of steel. The outer layer is high carbon steel with the chemical composition are 0.9 to $1.05 \% \mathrm{C}$. However, the middle layer has carbon composition of 0.08 to $1.3 \%$ [2]. Near to the surface of the double layer, the material contains martensite phase in the outer and ferrite in the inner, whereas martensite is consist of high carbon steel and ferrite is low carbon steel[3]. Figure 2 shown double layer steel. 


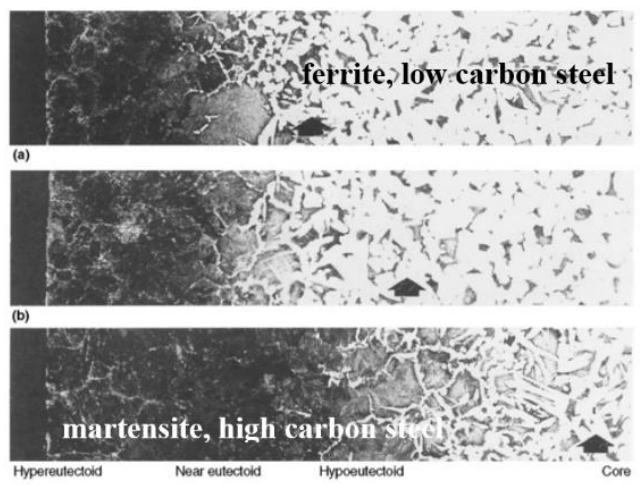

Fig. 3. Double layer microstructure consisting of martensite and ferrite [3]

The average chemical composition of moldboard plow material are shown in Table 1 was tested several times by using PMI Oxford Instrument.

Table 1. The Average chemical composition of moldboard plow

\begin{tabular}{|l|c|c|c|}
\hline Elements & Fe & Mn & C \\
\hline Composition (\%) & 99.53 & 0.360 & 0.11 \\
\hline
\end{tabular}

Chemical composition was tested at edge side and the middle side of the specimen. But the result indicated that carbon composition is very low.

\subsection{Simulation}

The Stress simulation was conducted by given the real boundary condition. Soil load to moldboard is the volume of soil times density $2.65 \mathrm{~g} / \mathrm{cm} 3$ and plow velocity $0.55 \mathrm{~m} / \mathrm{s}$. Hence, the load from soil to the moldboard is $92.896 \mathrm{~kg}$. The material is low carbon steel with the modulus of elasticity $200 \mathrm{GPa}$ [4]. Figure 2 is shown moldboard which was tested. At the edge tip of the corner is cut to make specimen that will be tested in the laboratory.

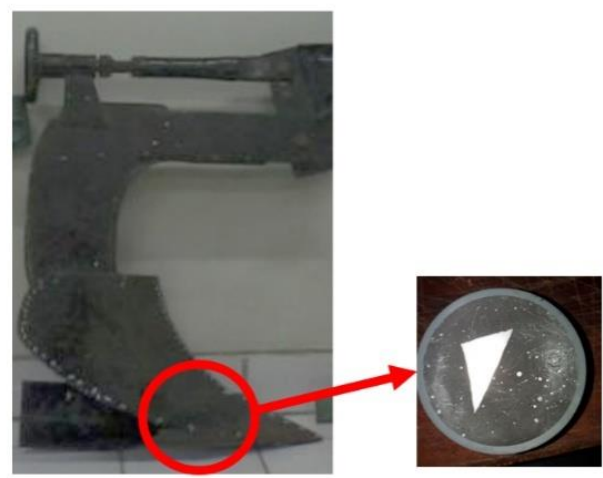

Fig. 4. Specimen moldboard plow

The stress analysis simulation is conducted using Solid Works 2017. The result of the simulation is shown in Figure 3 as follow. 


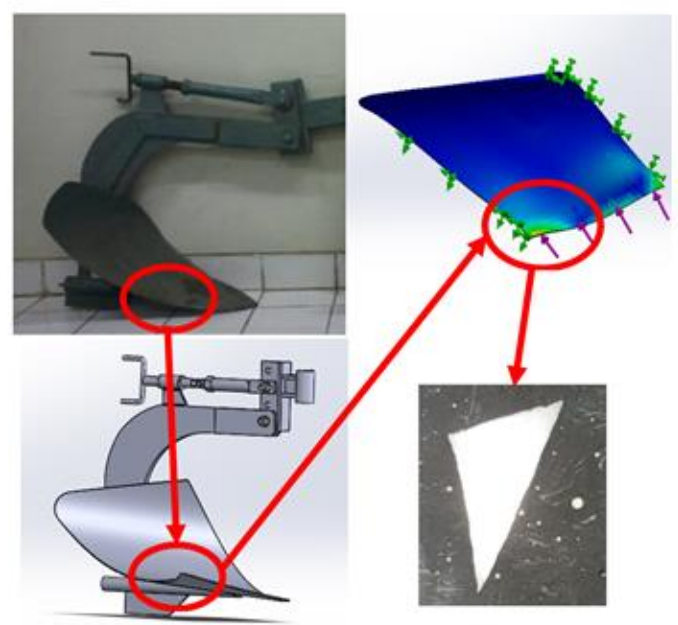

Fig. 5. The stress simulation of moldboard plow

From simulation shown that the critical area is at the edge tip in the corner. This area gets greater stress than other areas i.e. $713 \mathrm{MPa}$. While tensile strength material is 403 $\mathrm{MPa}$.

\subsection{Hardness Test}

Hardness test was conducted by using Rockwell $\mathrm{C}$ in the edge side area and the middle area of the moldboard. The result of the hardness test is shown in Figure 4.

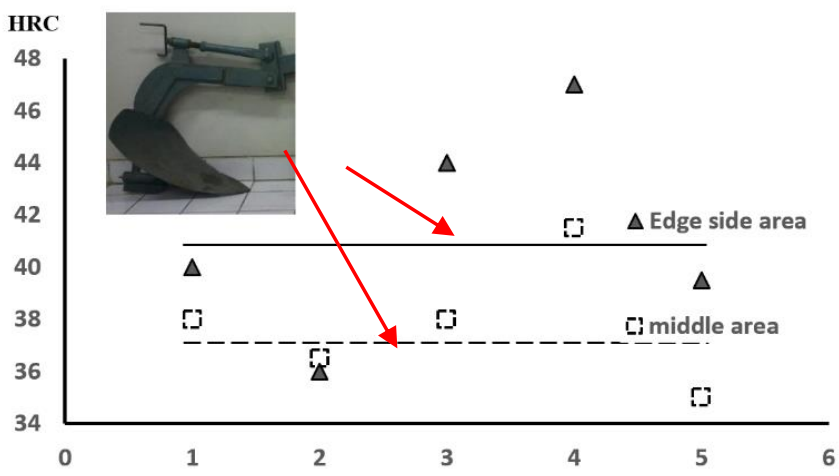

Fig. 6. Hardness graph by position tested

The graph in Figure 4 indicates that the average of the harness in the middle moldboard 37.8 HRC and in the edge side 41.3 HRC. The difference of the hardness value between that area is not very significant. 


\subsection{Micro Structure Observation}

Observation of microstructure is done by using an optical microscope. Prior to the observation, the specimen is cleaned and mounted using epoxy. Then the surface is flattened using abrasive papers up to grit 1200 .

\subsubsection{Non Etch Microstructure Observation}

In order to explain the mechanical properties phenomenon, microstructure examination is conducted to the moldboard specimen. The first examination was a non-etch condition to the middle and edge side area. Figure 5 showing the feature of the examination result.

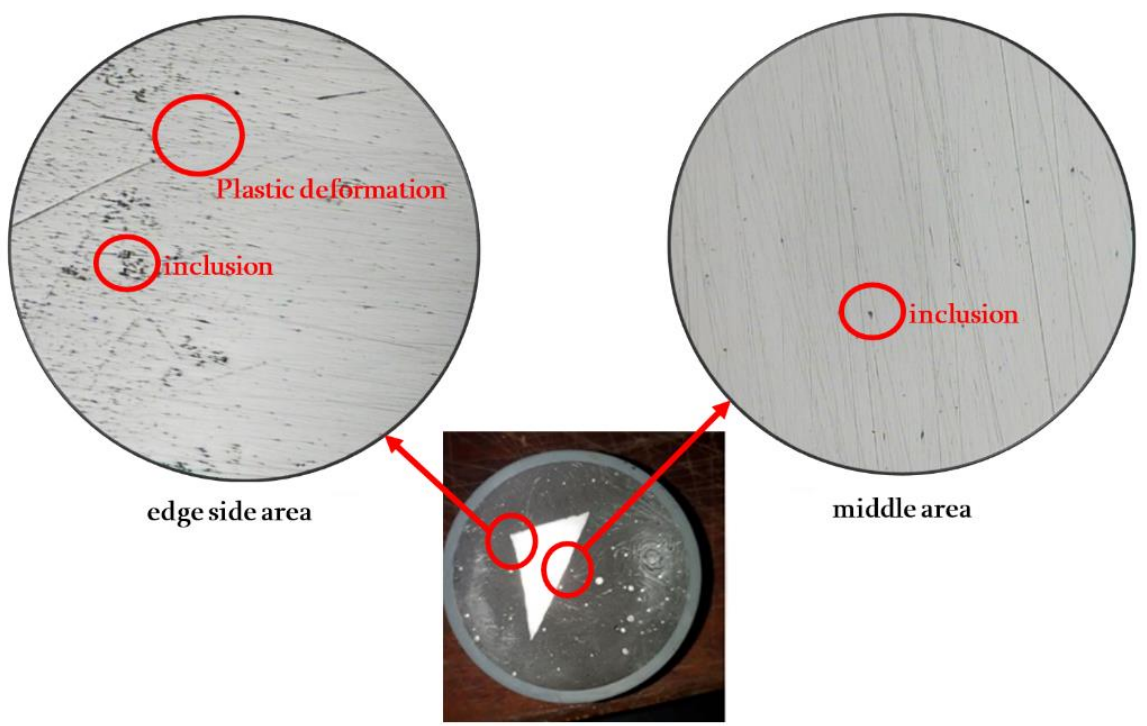

Fig. 7. The microstructure of the non-etch specimen, magnification 200x There are many inclusions and plastic deformation in the edge side more than in the middle side.

\subsubsection{Phase Structure Examination}

Phase structure examination is conducted to analyze physical properties of moldboard material. The etchant used is nital $4 \%$. Figure 6 shown the feature of phase structure in moldboard material. 


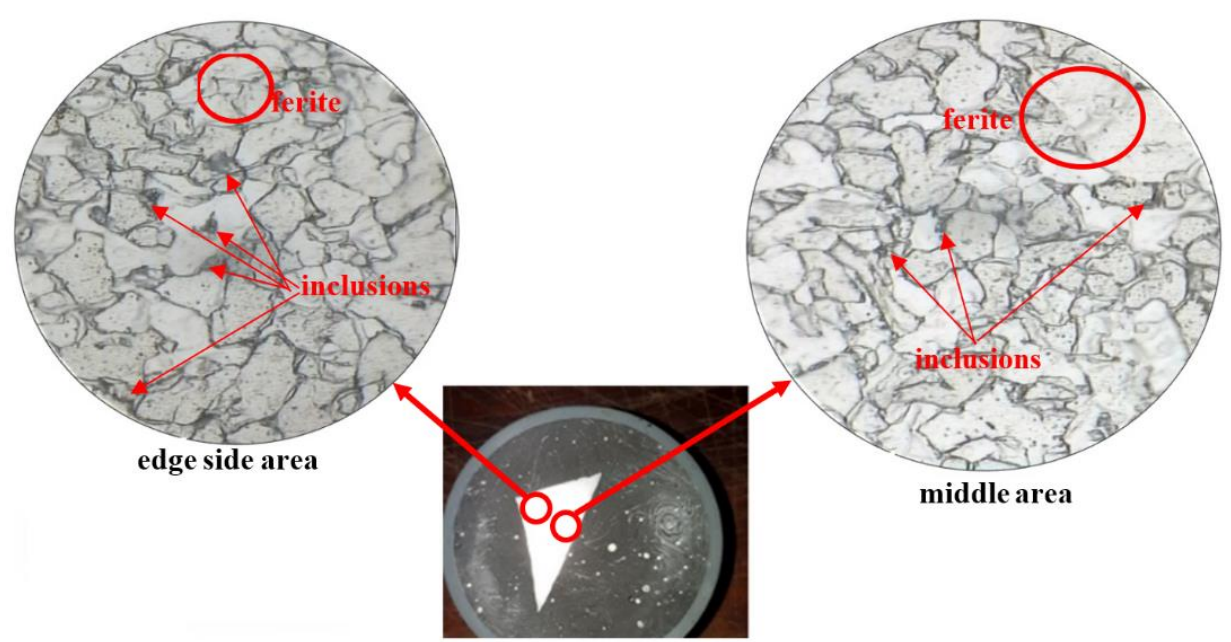

Fig. 8. Phase structure in moldboard material indicate inclusions and ferrite in a different size, magnification $1000 \mathrm{x}$

Inclusion is more dense on the edge of the moldboard than in the middle area. inclusion on the edge of the moldboard is more dense and more than in the middle area. In addition, the ferrite grain size is smaller because it is influenced by the moldboard manufacturing process.

\section{Results and Discussions}

The chemical composition of moldboard plow indicates that material is low alloy steel. This means that no high carbon steel layer on the outer side of the moldboard. Hence, moldboard is easy to plastic deformation because carbon steel is not strong enough to withstand forces during the plowing process.

The result of the stress analysis simulation is that the load received during the plowing process is greater than the tensile strength of the material. This suggests that the material is very susceptible to plastic deformation which will cause a deformation. Hence, moldboard material will easily experience cracks that cause damage.

Hardness test by Rockwell $\mathrm{C}$ shows that material has low HRC value i.e. 35 to 47. It is mean that tensile strength moldboard material only around $400 \mathrm{MPa}$. This reality has shown that why the moldboard easy to be damaged.

Non-etch microstructure analysis indicates that the edge side has inclusions denser than at the middle area. In the edge side area, inclusions are concentrate in many places. The inclusions inside to the moldboard material by diffusion from soil during plowing process. Meanwhile, impact forces from soil and matters contained in it cause plastic deformation in the edge side of the moldboard.

In the center of the moldboard, inclusion is not as much on the edge. This is because the interaction between the material and the surrounding soil is not accompanied by impact force at the edge side. Hence, the plastic deformation experienced is also not so great. However, it appears that the scratches on the surface of the specimen are due to the presence of manganese that forms the martensite phase.

Microstructure feature reveals that grain size on the edge side is little than the middle area. this show that the hardness value in the edge side slightly higher than in the middle. 


\section{Conclusion}

The cause of the damage is because the composition of carbon is too low and on the outside surface is not done heat treatment on the surface of the moldboard so that no martensite phase. should the material used to make the moldboard plow has been done the addition of carbon composition on the surface through carburization process that will form martensite phase plated outside the bottom plow.

\section{References}

1. Editorial, Evolution of the plow over 10,000 years and the rationale for no-till farming, (Soil Tillage Res)

2. David Gatende Gatumbi, Investigation of The Smearing Effect of Dull Moldboard Plow Shares (Quebec, 1984)

3. A. I. H. Committee, ASM HAND BOOK, (Metallography and Micro structur, 9th ed. Ohio USA: ASM International, 2004)

4. M. F. S. Hamed Shahmirzae Jeshvaghani, Salman Khaksar Haghani Dehkordi and Hamidreza Rafeie Dehkordi. J. Am. Sci. 6 (2013) 